\title{
Severe methemoglobinemia from topical anesthetic spray: case report, discussion and qualitative systematic review
}

\author{
Riyad B. Abu-Laban, MD, MHSc;* Peter J. Zed, BSc (Pharm), PharmD; $\dagger$ Roy A. Purssell, MD;* \\ Kenneth G. Evans, MD
}

\begin{abstract}
Few health care professionals realize that topical anesthetic spray can cause methemoglobinemia. We describe a 56-year-old woman who was transferred to our emergency department when severe cyanosis and chest pain developed after administration of topical oropharyngeal benzocaine and lidocaine during outpatient endoscopy. Investigations revealed a methemoglobin level of $51 \%$. Despite rapid diagnosis and treatment with methylene blue, pulmonary edema consistent with adult respiratory distress syndrome developed, endotracheal intubation was required, and the patient suffered a lengthy course in the intensive care unit. This article presents a detailed discussion of the pathophysiology, diagnosis and treatment of methemoglobinemia, as well as a qualitative systematic review of the English literature on methemoglobinemia induced by topical anesthetic. The implications of this condition for emergency physicians are also outlined.

\section{RÉSUMÉ}

Peu de professionnels de la santé savent qu'un anesthésique local en aérosol peut provoquer une méthémoglobinémie. Nous décrivons le cas d'une femme de 56 ans qui fut transférée vers notre département $d$ 'urgence lorsqu'une cyanose sévère et une douleur thoracique se manifestèrent après l'administration topique de benzocaïne et de lidocaïne oropharyngées au cours d'une endoscopie en consultation externe. Des épreuves révélèrent un taux de méthémoglobinémie à $51 \%$. Malgré le diagnostic rapide et un traitement à l'aide de bleu de méthylène, un œdème pulmonaire se produisit, indiquant un syndrome de détresse respiratoire de l'adulte. La patiente dut subir une intubation endotrachéale et demeura aux soins intensifs pendant plusieurs jours. Le présent article offre une discussion détaillée de la physiopathologie, du diagnostic et du traitement de la méthémoglobinémie provoquée par un anesthésique local. On dresse également un aperçu des implications de cette affection pour les médecins d'urgence.
\end{abstract}

Key words: methemoglobinemia, pulmonary edema, adult respiratory distress syndrome, benzocaine, lidocaine, topical administration, anesthetic, emergency department

\section{Case report}

A 56-year-old woman was urgently transferred from an outpatient endoscopy suite to our emergency department (ED) because of severe cyanosis and chest pain. She was a smoker and had a history of alcohol abuse, seizures, coronary artery disease and chronic obstructive pulmonary disease.
Her medications included beclomethasone, ipratropium bromide and salbutamol, all administered by inhaler. She had no known allergies or drug sensitivities and no history of congestive heart failure.

The patient presented to the endoscopy suite at 1040, 2 hours and 20 minutes before her eventual transfer to the ED. At that time she felt completely well and had an oxy-

The Departments of *Emergency Medicine, †CSU Pharmaceutical Sciences, and ¥Thoracic Surgery, Vancouver General Hospital, Vancouver, BC Received: Nov. 30, 1999; final submission: Sept. 22, 2000; accepted: Oct. 5, 2000.

This article has been peer reviewed. 
gen saturation of $97 \%$ by pulse oximetry. She was premedicated with a single oropharyngeal spray of $20 \%$ benzocaine (Hurricaine Spray), as well as topical oropharyngeal lidocaine spray (4 metered doses of $10 \mathrm{mg} / \mathrm{dose}$ ) and intravenous diazepam (15 mg). The procedure, an esophageal dilatation, was uneventful.

The patient was taken to the recovery room at 1135 , 45 minutes after the premedication drugs were given. Within 5 minutes, she became agitated and hypoxic, with an oxygen saturation of $89 \%$ by pulse oximeter. Oxygen and nebulized salbutamol were administered, but her condition deteriorated, and profound cyanosis developed despite administration of high-flow oxygen. She then began to experience chest pain and was given nitroglycerin, $0.6 \mathrm{mg}$ sublingual, followed by morphine $1 \mathrm{mg}$ intravenously (IV). An electrocardiogram (ECG) showed nonspecific ST changes, and the chest $\mathrm{x}$-ray was unremarkable. At this point she was transferred urgently to the ED with a presumptive diagnosis of pulmonary embolism or myocardial infarction.

On arrival in the ED at 1300, the patient was severely distressed and had profound cyanosis despite administration of $100 \%$ oxygen. She reported continuous, burning, nonradiating central chest pain unrelated to respirations, position or movement, for which she was given serial doses of sublingual nitroglycerin spray. She denied abdominal or extremity pain.

On examination, her pulse was 120 beats/min, respiratory rate 32 breaths/min and blood pressure 118/62 $\mathrm{mm} \mathrm{Hg}$. Oxygen saturation was $90 \%$ by pulse oximetry, and she was confused, with a score of 14 on the Glasgow Coma Scale. Air entry was normal and symmetric, with fine bibasal crepitations. Heart sounds were normal without murmurs, and her abdomen was soft and nontender. Examination of the extremities revealed no edema and no evidence of deep vein thrombosis. The musculoskeletal and nervous systems were normal.

At this time, a repeat ECG showed T-wave inversions in leads V1, V2 and V3, with (less than $1 \mathrm{~mm}$ of) ST elevation in leads III and AVF. Arterial blood gas analysis revealed a $\mathrm{pH}$ of $7.40, \mathrm{PO}_{2}$ of $342 \mathrm{~mm} \mathrm{Hg}, \mathrm{PCO}_{2}$ of $37 \mathrm{~mm} \mathrm{Hg}$ and oxygen saturation of $47 \%$ by co-oximeter. Because of the unexpectedly high $\mathrm{PO}_{2}$ in the face of profound cyanosis, and the discordance between the pulse oximeter and co-oximeter saturation values, carboxyhemoglobin and methemoglobin levels were immediately performed, revealing values of $0 \%$ and $51 \%$ respectively. Ten minutes after the patient's arrival, methylene blue was ordered - stat - and following a 20-minute delay to acquire the drug from the pharmacy, $140 \mathrm{mg}$ ( $2 \mathrm{mg} / \mathrm{kg}$ ) was administered IV over 5 minutes.

Within 10 minutes, the patient's colour improved, and she appeared less distressed. Repeat arterial blood gas testing at 1345 revealed a $\mathrm{pH}$ of $7.31, \mathrm{PO}_{2}$ of $52 \mathrm{~mm} \mathrm{Hg}, \mathrm{PCO}_{2}$ of $29 \mathrm{~mm} \mathrm{Hg}$ and an oxygen saturation of $74 \%$ by cooximeter. The methemoglobin level had fallen to $15 \%$. Over the next 45 minutes, however, the patient's status worsened dramatically with the development of severe respiratory distress, profound acidosis and pulmonary edema consistent with adult respiratory distress syndrome (ARDS). Furosemide $40 \mathrm{mg}$ IV was administered, and she was endotracheally intubated in rapid-sequence fashion after the administration of fentanyl $(250 \mu \mathrm{g})$, midazolam $(5 \mathrm{mg})$ and succinylcholine $(120 \mathrm{mg})$. She received intravenous atropine ( $1 \mathrm{mg}$ ) and epinephrine (3 doses of $0.1 \mathrm{mg}$ ) because of episodic bradycardia and hypotension, then was transferred to the intensive care unit (ICU). She remained intubated in the ICU for 12 days and received repeat doses of methylene blue during the early phase of her stay. There was no ECG or enzyme evidence of myocardial infarction, and she was discharged from the hospital without neurologic or cardiorespiratory sequelae 18 days after her initial presentation to the ED. On follow-up evaluations the patient remained well.

\section{Discussion}

\section{Hemoglobin and methemoglobin}

Hemoglobin is comprised of 4 heme groups, each containing an iron atom. Each atom is capable of binding oxygen, but such binding can occur only if the iron is in the reduced state $\left(\mathrm{Fe}^{2+}\right)$. Removal of an electron from a reduced iron atom (oxidation: $\mathrm{Fe}^{2+}$ to $\mathrm{Fe}^{3+}$ ) produces methemoglobin, which is incapable of binding oxygen. Moreover, the production of a ferric $\left(\mathrm{Fe}^{3+}\right)$ heme group interferes with oxygen unloading by the other ferrous $\left(\mathrm{Fe}^{2+}\right)$ heme groups on the hemoglobin moiety. This causes the oxyhemoglobin curve to shift to the left. ${ }^{1}$

Under physiologic circumstances methemoglobin is continuously produced as a result of the oxidizing effect of oxygen; however, it is rapidly converted back to hemoglobin, predominantly by cytochrome-b5 reductase (a.k.a. NADHdependent methemoglobin reductase). As a result, methemoglobin levels are normally less than $2 \%$. Five g/dL of deoxyhemoglobin is required to produce cyanosis, but because of the spectrographic properties of methemoglobin, the latter compound produces visible skin discoloration at a level of only $1.5 \mathrm{~g} / \mathrm{dL} .{ }^{1}$

Rare forms of congenital methemoglobinemia exist, but most cases of methemoglobinemia in adults are secondary to drugs or toxic agents. The most commonly used drugs that cause methemoglobinemia are benzocaine, lidocaine, pri- 
locaine, dapsone, amyl nitrate, isobutyl nitrate, nitroglycerin, nitroprusside, primaquine, sulfonamides and phenazopyridine. It is not generally appreciated that therapeutic doses of most local anesthetics (given topically or intravenously) can produce this condition. In the case presented, methemoglobinemia was clearly due to the topical local anesthetic, as the only other new agent that the patient received was diazepam, a drug not associated with the condition.

\section{Diagnosis}

The definitive diagnostic test for methemoglobinemia is multiple-wavelength co-oximetry. Co-oximeters measure the light absorption of blood at numerous ultraviolet wavelengths. As a result, these machines are able to determine the percentages of oxyhemoglobin, deoxyhemoglobin, carboxyhemoglobin and methemoglobin. A multiple-wavelength co-oximeter is different from a pulse oximeter, which measures ultraviolet absorption at only two wavelengths (940 and $660 \mathrm{~nm}$ ) to differentiate oxyhemoglobin and deoxyhemoglobin. ${ }^{1}$ Pulse oximeters are designed for continuous noninvasive monitoring, whereas co-oximeters require a blood sample and are typically available only at tertiary care centres.

A standard blood gas machine will not detect methemoglobin. Such machines measure oxygen tension $\left(\mathrm{PO}_{2}\right)$ and $\mathrm{pH}$, then calculate oxygen saturation from these values. This approach assumes the absence of abnormal hemoglobin. To complicate matters, pulse oximeters are unreliable in the presence of methemoglobin, because methemoglobin is detected by both the oxyhemoglobin $(940 \mathrm{~nm})$ and deoxyhemoglobin $(660 \mathrm{~nm})$ sensors of the oximeters. At low levels $(<20 \%)$, methemoglobin is detected primarily by the deoxyhemoglobin sensor, and a pulse oximeter may show a falsely low oxygen saturation. At high methemoglobin levels $(>70 \%)$, detection by the oxyhemoglobin sensor predominates, and a pulse oximeter may show a falsely high reading. ${ }^{2}$ Of note, methylene blue, the antidote for methemoglobinemia, is also detected by the pulse oximeter's deoxyhemoglobin sensor, which leads to the potential for falsely low post-treatment oxygen saturation readings. ${ }^{2}$ One group of investigators compared oxygen saturation measurements by multiple-wavelength co-oximetry and pulse oximetry at various methemoglobin levels in a canine model. ${ }^{3}$ They found that pulse oximeter measurements overestimated oxygen saturation and that as the methemoglobin level rose, the pulse oximeter became increasingly insensitive to changes in oxygen saturation. In the case we have presented, pulse oximetry readings were falsely reassuring (90\%) despite a methemoglobin level of $51 \%$.

Because multiple-wavelength co-oximetry is not univer- sally available, emergency physicians should be aware of other clinical findings and laboratory tests suggestive of methemoglobinemia. Clinical findings include cyanosis that is unresponsive to oxygen and cyanosis in the presence of normal (calculated) oxygen saturation. Although pulse oximeter readings are inaccurate in this circumstance, oximeter saturation values that deviate substantially from the clinical picture may suggest the diagnosis. In addition, if the difference between the calculated oxygen saturation from a standard blood gas machine and the reading from a pulse oximeter is greater than 5\%, it is likely that the patient has an abnormal hemoglobin (either carboxyhemoglobin, methemoglobin or sulfhemoglobin; cyanohemoglobin does not result in this finding). Some authors refer to this as a "saturation gap," whereas others use this term for the difference between the calculated oxygen saturation from a standard blood gas machine and the measured value from a co-oximeter. Detection of the first type of saturation gap can be clinically useful; detection of the latter type is less so, because availability of a co-oximeter measurement implies the ability to directly measure methemoglobin.

Although unexpected pulse oximeter readings may prompt consideration of the diagnosis of methemoglobinemia, oximeters should not be assumed to be accurate; nor should they be used to monitor patients if abnormal hemoglobins are suspected or confirmed. Moreover, if a saturation gap is found, it will not necessarily be proportional to the actual methemoglobin level (for example, a pulse oximetry saturation of $85 \%$ does not imply that the methemoglobin level is only $15 \%$ ).

\section{Treatment}

Symptomatic patients with methemoglobinemia, particularly those with levels over $20 \%$, should receive methylene blue, which acts as a cofactor for the enzyme NADPH methemoglobin reductase. Electrons are transferred from NADPH to methylene blue, which leads to a reduction of the heme iron, in the form of deoxyhemoglobin (Fig. 1). Methylene blue should not be administered to patients with severe glucose-6-phosphate dehydrogenase (G6PD) deficiency. These patients have low levels of NADPH, so methylene blue is ineffective and will cause hemolysis. There is no easily accessible laboratory test for G6PD deficiency; thus, when possible, patients should be directly asked about this condition.

Methylene blue should be administered at an initial dose of 1 to $2 \mathrm{mg} / \mathrm{kg}$ ( 0.1 to $0.2 \mathrm{~mL} / \mathrm{kg}$ of a $1 \%$ solution) over 3 to 5 minutes, followed by a 15 - to $30-\mathrm{mL}$ fluid flush. ${ }^{4,5}$ Resolution of cyanosis usually occurs within 20 minutes. If there is no response and the patient has serious symptoms, 
a repeat $1 \mathrm{mg} / \mathrm{kg}$ dose may be administered after 30 to 60 minutes. ${ }^{5}$ Side effects of methylene blue include bluish skin discoloration (complicating the assessment of cyanosis), hemolysis, gastrointestinal distress, bladder irritation and, ironically, methemoglobinemia (particularly in doses above $7 \mathrm{mg} / \mathrm{kg}$ ). Failure to respond to methylene blue may reflect an incorrect diagnosis (e.g., sulfhemoglobinemia), inadequate gastrointestinal decontamination with ongoing toxin absorption, G6PD deficiency, congenital NADPH methemoglobin reductase deficiency, or a unique toxin such as analine or doprane (which cause prolonged absorption and cyclic methemoglobin production), phenylhydroxylamine (which blocks methylene blue uptake) or hydroxylamine (which blocks methylene blue uptake and inhibits NADPH methemoglobin reductase). In selected cases of unresponsive methemoglobinemia, the use of hyperbaric oxygen or exchange transfusion may be warranted. ${ }^{5}$ In the patient described, the cyanosis and methemoglobin level improved rapidly after administration of methylene blue; however, the development of ARDS, presumably from prolonged pulmonary hypoxia, led to a worsening of the clinical status.

\section{Qualitative systematic review}

To evaluate the described experience with methemoglobinemia secondary to topical anesthetic agents, we performed a qualitative systematic review of the English literature. We reviewed the electronic databases of MEDLINE
(January 1966 to August 2000) and EMBASE (January 1988 to August 2000) using the search terms "methemoglobinemia," "topical administration," "anesthetic," "benzocaine" and "lidocaine." The reference lists from reports obtained from this search were hand searched to identify additional papers. All reports describing adults (over 18 years of age) with methemoglobinemia caused by topical anesthesia were reviewed and summarized by a single author (P.J.Z.).

Thirty-seven papers describing 44 cases met our inclusion criteria. ${ }^{6-42}$ The cases involved 30 men and 14 women from 24 to 84 years of age. The causative agent was Hurricaine Spray (benzocaine 20\%) in 25 cases; Cetacaine (benzocaine $14 \%$ with tetracaine 2\%) in 10 cases; a mixture of benzocaine spray (14\% or $20 \%$ ) with a viscous or spray lidocaine formulation in 5 cases; and benzocaine topical cream, gel or gargle in 3 cases. In one case the agent was not specified. Most cases involved esophagoscopy, bronchoscopy or endotracheal intubation.

In 41 cases involving topical spray, symptoms developed within 20 minutes of administration in 30 cases (73\%), within 60 minutes in 36 cases (88\%), and within 2 hours in $100 \%$ of cases. Methemoglobin concentrations ranged from $19 \%$ to $75 \%$, and one death, from irreversible shock 24 hours after the onset of symptoms, was reported. Cyanosis was present in all cases. Other clinical findings reported included agitation, confusion, headache, dizziness, weakness, dyspnea, epigastric pain and hypotension. In 2 cases, ECG

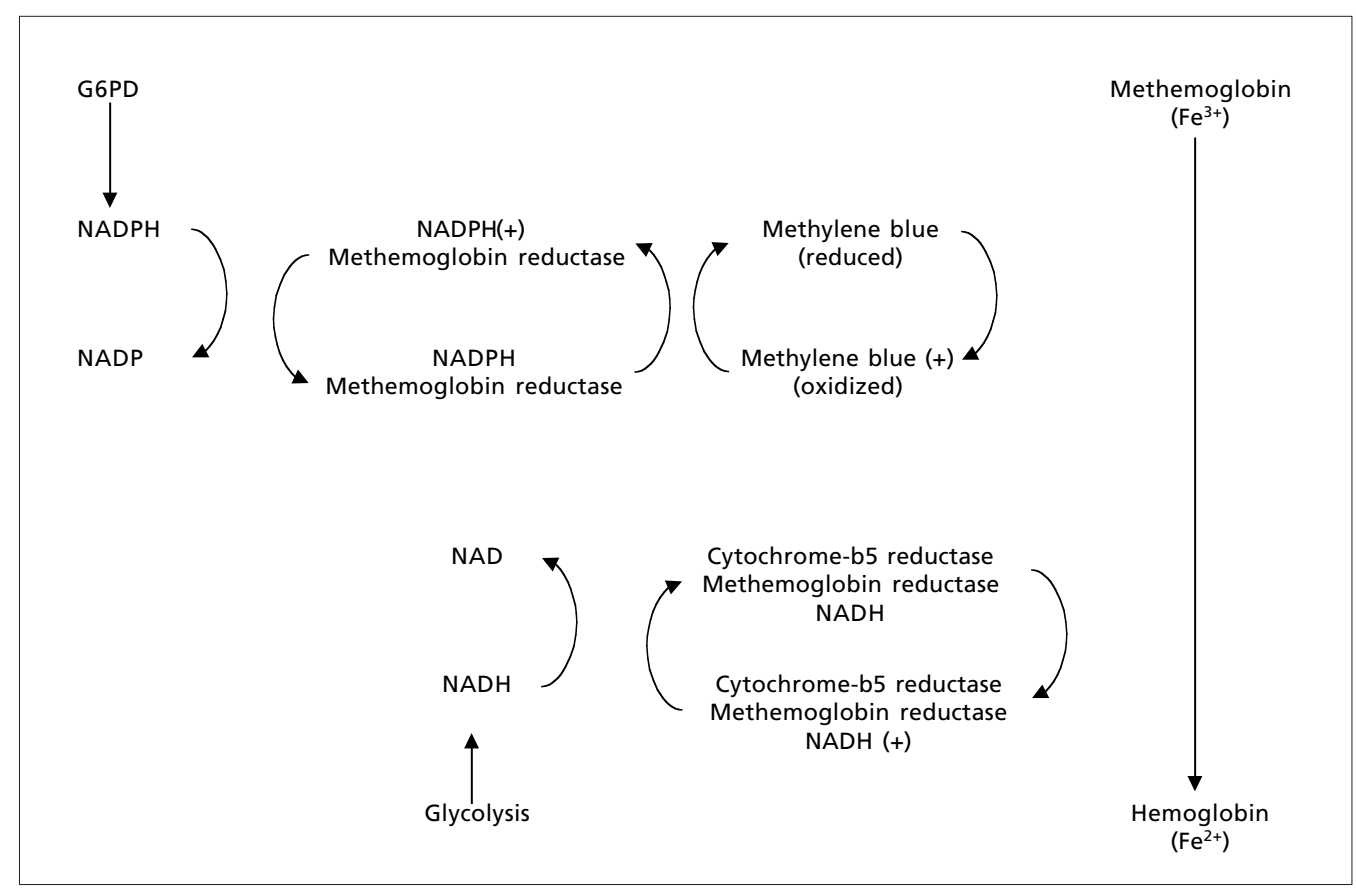

Fig. 1. Methemoglobin production and action of methylene blue 
evidence of myocardial ischemia was reported. Many of the case reports noted a poor correlation between pulse oximeter and co-oximeter readings. Methylene blue was administered as a single IV dose of 1 to $2 \mathrm{mg} / \mathrm{kg}$ in $36(82 \%)$ of the 44 cases. In 4 cases, a benzocaine rechallenge led to a recurrence of methemoglobinemia. ${ }^{11,33,37,41}$

\section{Conclusions}

The case of methemoglobinemia we presented is consistent with others described in the literature, although the associated chest pain (likely from myocardial ischemia) and ARDS (likely from pulmonary hypoxia) were unique. Since all previously described cases of methemoglobinemia from topical anesthetic involved benzocaine, and because there is no compelling evidence for the role of lidocaine as a solo inducer, we conclude that this case was almost certainly due to the benzocaine spray.

It is clear from this case and the literature reviewed that therapeutic doses of topical anesthetic agents can cause methemoglobinemia. It is also clear from our discussions with other emergency physicians that most are unaware of this important fact. This topic is highly relevant to emergency medicine. EDs often stock benzocaine as an alternative agent for lidocaine-allergic patients and because of its more palatable taste. Emergency physicians frequently use topical anesthetic agents for awake intubation and direct or indirect laryngoscopy. In addition, patients who receive these agents for procedures in outpatient areas of the hospital are likely to be transferred to the ED if problems develop, as happened in the case presented. As a result, it is important for emergency physicians to be aware of this serious idiosyncratic reaction and to have knowledge of the presentation, diagnosis and treatment of methemoglobinemia. Finally, as our case illustrates, the time delay to acquire drugs from a hospital pharmacy can be a factor in critical situations; thus, we feel that methylene blue should be among the antidotes immediately available in the ED. To reduce delays in administration, our ED has added to ward stock sufficient methylene blue for an initial $2 \mathrm{mg} / \mathrm{kg}$ dose.

Acknowledgement: The authors thank Dr. Jeffrey Brubacher for his assistance in the preparation of this paper.

\section{References}

1. Curry A, Carlton M. Hemotologic consequences of poisoning. In: Haddad LM, Shannon MW, Winchester JF, editors. Clinical management of poisoning and overdose, 3rd ed. Philadelphia: WB Saunders; 1998. p. 223-35.
2. Watcha MF, Connor MT, Hing AV. Pulse oximetry and methemoglobinemia. AJDC 1989;143:845-7.

3. Barker SJ, Tremper SJ, Hyatt J, Zaccari J. Effects of methemoglobinemia on pulse oximetry and mixed venous oximetry. Anesthesiol 1987;67(3A):A171.

4. Howland MA. Antidotes in depth: methylene blue. In: Goldfrank LR. Goldfrank's toxocologic emergencies, 5th ed. Norwalk: Appleton and Lange; 1994. p. 1179-80.

5. Blanc PD. Methemoglobinemia. In: Olson KR, editor. Poisoning and drug overdose, 3rd ed. Norwalk: Appleton \& Lange; 1999. p. 217-9.

6. Fisher MA, Henry D, Gillam L, Chen C. Toxic methemoglobinemia: a rare but serious complication of transesophageal echocardgiography. Can J Cardiol 1998;14:1157-60.

7. Malhotra S, Kolda M, Nanda NC. Local anesthetic-induced methemoglobinemia during transesophageal echocardiography. Echocardiography 1998;15:165-7.

8. Ho RT, Nanevicz T, Yee R, Figueredo VM. Benzocaine-induced methemoglobinemia: two case reports related to transesophageal echocardiography premedication. Cardiovasc Drugs Ther 1998; $12: 211-2$

9. Maher P. Methemoglobinemia: an unusual complication of topical anesthesia. Gastroenterol Nurs 1998;21:173-5.

10. Clary B, Skaryak L, Tedder M, Hilton A, Botz G, Harpole D. Methemoglobinemia complicating topical anesthesia during bronchoscopic procedures. J Thorac Cardiovasc Surg 1997;114: 293-5.

11. Cooper HA. Methemoglobinemia caused by benzocaine topical spray. South Med J 1997;90:946-8.

12. Guerriero SE. Methemoglobinemia caused by topic benzocaine. Pharmacotherapy 1997;17:1038-40.

13. Ferraro-Borgida MJ, Mulhern SA, DeMeo MO, Bayer MJ. Methemoglobinemia from perineal application of anesthetic cream. Ann Intern Med 1997;27:785-8.

14. Gilman CS, Veser FH, Randall D. Methemoglobinemia from topical oral anesthetic. Acad Emerg Med 1997;4:1011-3.

15. Shua-Haim JR, Wyszkowski R, Gross JS. Unusual case of methemoglobinemia in an elderly patient following topical spray of benzocaine. Clin Geriatr 1996;4:78-85.

16. Grauer SE, Girard GD. Toxic methemoglobinemia after topic anesthesia for transesophageal echocardiography. J Am Soc Echocardiogr 1996;9:874-6.

17. Lee E, Boorse R, Marcinczyk M. Methemoglobinemia secondary to benzocaine topical anesthetic. Surg Laparosc Endosc 1996; 6:492-3.

18. Ellis FD, Seiler JG, Palmore MM. Methemoglobinemia: a complication after fiberoptic orotracheal intubation with benzocaine spray. J Bone Joint Surg 1995;77:937-9.

19. Brown CM, Levy SA, Susann PW. Methemoglobinemia: lifethreatening complication of endoscopy premedication. Am J Gastroenterol 1994;89:1108-9. 
20. Dinneen SF, Mohr DN, Fairbanks VF. Methemoglobinemia from topically applied anesthetic spray. Mayo Clin Proc 1994; 69:886-8.

21. Rodriguez LF, Smolik LM, Zbehlik AJ. Benzocaine-induced methemoglobinemia: report of a severe reaction and review of the literature. Ann Pharmacother 1994;28:643-9.

22. Vessely MB, Zitsch III RP. Topical anesthetic-induced methemoglobinemia: a case report and review of the literature. Otolaryngol Head Neck Surg 1993;108:763-7.

23. Muchmore EA, Dahl BJ. One blue man with mucositis. N Engl J Med 1992;327:133.

24. Marcovitz PA, Williamson B, Armstrong WF. Toxic methemoglobinemia caused by topical anesthetic given before transesophageal echocardiography. J Am Soc Echocardiogr 1991;4:6158.

25. Linares LA, Peretz TY, Chin J. Methemoglobinemia induced by topical anesthetic (benzocaine). Radiother Oncol 1990;18:267-9.

26. Collins JF. Methemoglobinemia as a complication of $20 \%$ benzocaine spray for endoscopy. Gastroenterol 1990;98:211-3.

27. Grum DF, Rice TW. Methemoglobinemia from topical benzocaine. Cleve Clin J Med 1990;57:357-9.

28. Kotler R, Hansen-Flaschen J, Casey MP. Severe methemoglobinemia after flexible fibreoptic bronchoscopy. Thorax 1989; 44:234-5.

29. Ferraro L, Zeichner S, Greenblott G, Groeger JS. Cetacaineinduced acute methemoglobinemia. Anesthesiology 1988;69: 614-5.

30. Anderson ST, Hajduczek J, Barker SJ, Benzocaine-induced methemoglobinemia in an adult: accuracy of pulse oximetry with methemoglobinemia. Anesth Analg 1988;67:1099-101.

31. Buckley AB, Newman A. Methemoglobinemia occurring after the use of $20 \%$ benzocaine topical anesthetic spray prior to gastroscopy. Gastrointest Endosc 1987;33:466-7.
32. Speilman FJ, Anderson JA, Terry WC. Benzocaine-induced methemoglobinemia during general anesthesia. J Oral Maxillo Surg 1984;42:740-3.

33. Olson ML, McEvoy GK. Methemoglobinemia induced by local anesthetics. Am J Hosp Pharm 1981;38:89-93.

34. Sandza JG, Roberts RW, Shaw RC, Connors JP. Symptomatic methemoglobinemia with a commonly used topical anesthetic spray. Ann Thorac Surg 1980;30:187-90.

35. O’Donohue WJ, Moss LM, Angelillo VA. Acute methemoglobinemia induced by topical benzocaine and lidocaine. Arch Inten Med 1980;140:1505-9.

36. Douglas WW, Fairbanks VF. Methemoglobinemia induced by a topical anesthetic spray (cetacaine). Chest 1977;71:587-91.

37. Khan NA, Kruse JA. Methemoglobinemia induced by topical anesthesia: a case report and review. Am J Med Sci 1999;318: 415-8.

38. Slaughter MS, Gordon PJ, Roberts JC, Pappas PS. An unusual case of hypoxia from benzocaine-induced methemoglobinemia. Ann Thorac Surg 1999;67:1776-8.

39. Nguyen ST, Cabrales RE, Bashour A, Rosenberger TE, Michener JA, Yared J-P, Starr NJ. Benzocaine-induced methemoglobinemia. Anesth Analg 2000;90:367-71.

40. Wurdeman RL, Mohiuddin SM, Holmberg MJ, Shalaby A. Benzocaine-induced methemoglobinemia during and outpatient procedure. Pharmacotherapy 2000;20:735-8.

41. Gupta PM, Lala DS, Arsura EL. Benzocaine-induced methemoglobinemia. South Med J 2000;93:83-6.

42. Haynes JM. Acquired methemoglobinemia following benzocaine anesthesia of the pharynx. Am J Crit Care 2000;9:199-201.

Correspondence to: Dr. Riyad B. Abu-Laban, Department of Emergency Medicine, Vancouver General Hospital, 855 W 12th Ave., Vancouver BC V5Z 1M9; abulaban@interchange.ubc.ca.
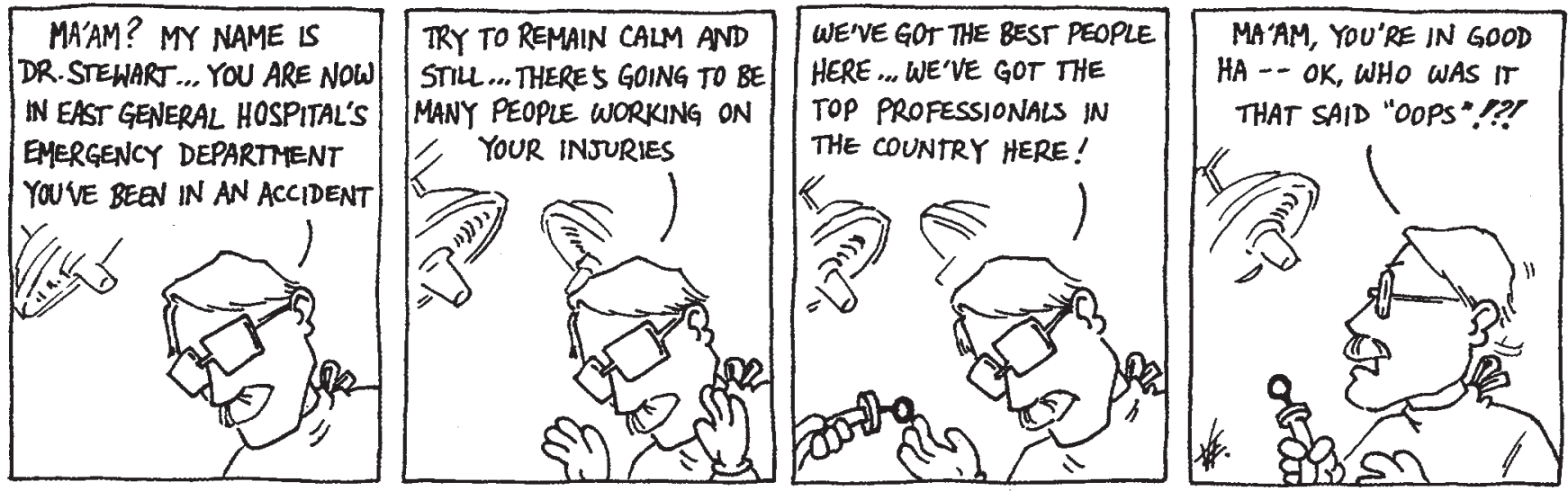